\title{
Oxidation stability: the bottleneck for the development of a fully renewable biofuel from wine industry wastes
}

David Donoso $^{1}$, David Bolonio ${ }^{2}$, Magín Lapuerta ${ }^{1 *}$ and Laureano Canoira ${ }^{2}$.

${ }^{1}$ Grupo de Combustibles y Motores, ETS Ingeniería Industrial. Universidad de Castilla-La Mancha. Avda. Camilo José Cela 2, 13071 Ciudad Real, Spain.

${ }^{2}$ Department of Energy \& Fuels, ETS Ingenieros de Minas y Energía, Universidad Politécnica de Madrid. Ríos Rosas 21, 28003 Madrid, Spain.

\section{Supporting Information}

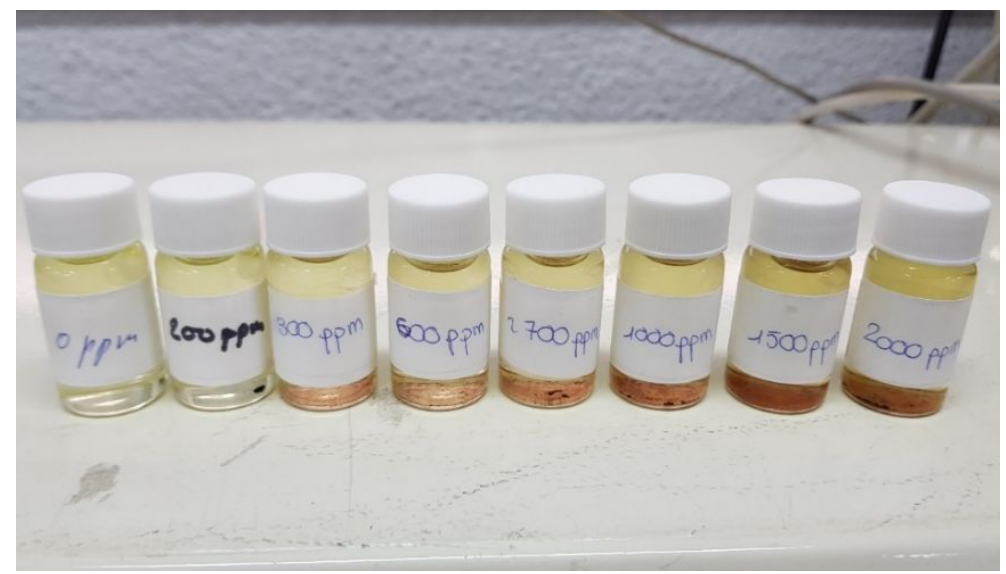

Figure S1. FAEE samples additivated with natural antioxidants extracted from defatted grapeseed flour (red solid at the bottom) (additivation dosages labelled in the vials correspond to target values) 

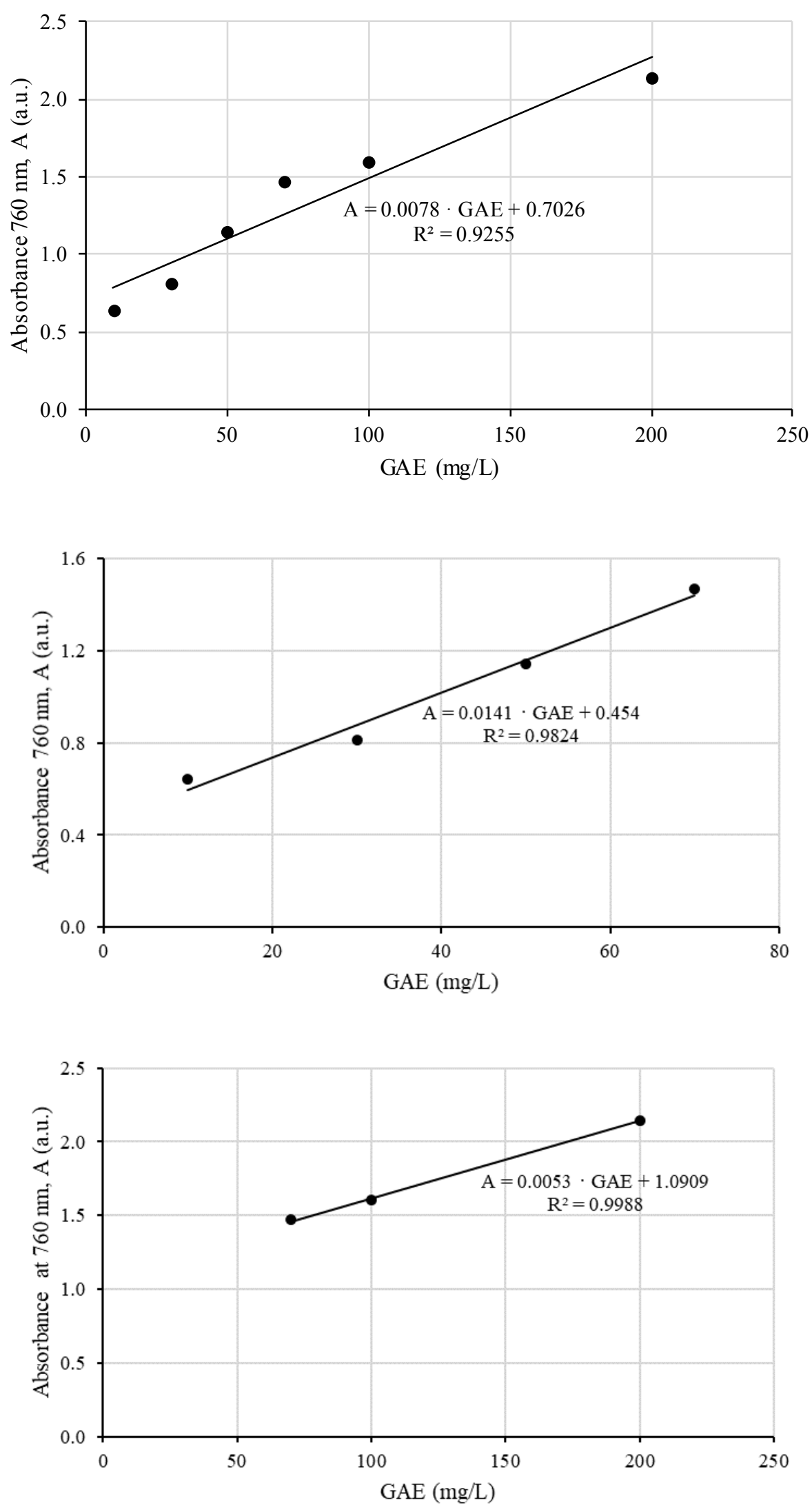

Figure S2. Calibration of gallic acid solutions (the full range of calibration, top, has been divided into two sub-ranges, bottom, for a better linear adjustment) 

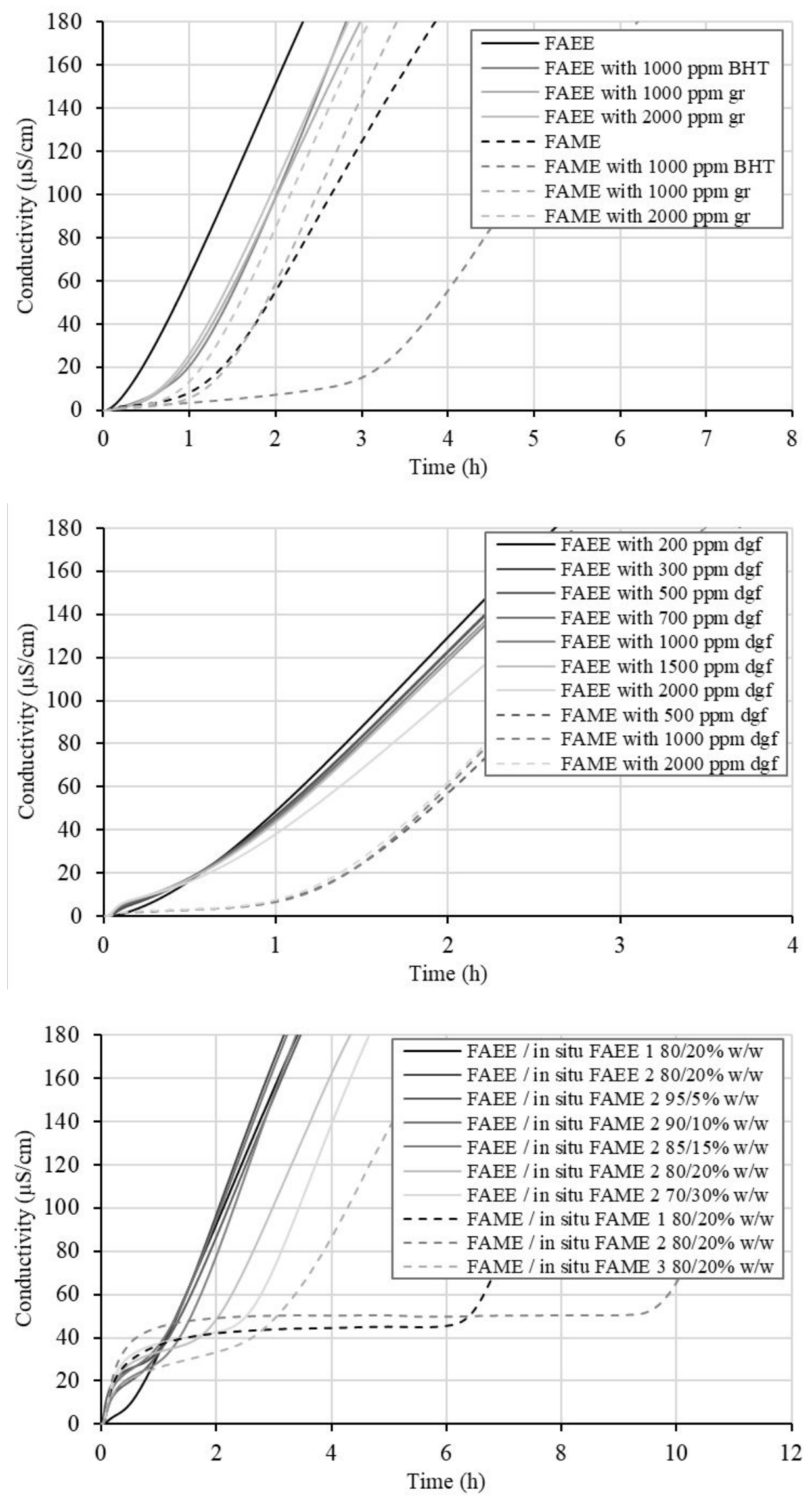

Figure S3. Accelerated oxidation curves (conductivity vs. time) obtained from the Rancimat test 